\title{
Pao Pereira extract suppresses benign prostatic hyperplasia by inhibiting inflammation-associated NFKB signaling
}

Yu Dong ${ }^{1,2+}$, Jiakuan Liü ${ }^{3+}$, Zesheng Xue ${ }^{3+}$, Jingya Sun ${ }^{2}$, Zhengnan Huang ${ }^{4}$, Yifeng Jing ${ }^{4}$, Bangmin Han $^{4}$, Bing Shen ${ }^{4^{*}}$, Jun Yan ${ }^{5,6^{*}}$ and Ruimin Huang ${ }^{2,7^{*}}$ (i)

\begin{abstract}
Background: Our previous study revealed the extract from the bark of an Amazonian tree Pao Pereira can suppress benign prostatic hyperplasia (BPH) in a rat model. Herein, we examined its inhibitory effects on human BPH cells and dissect its molecular mechanism.

Methods: We applied Pao extract to human BPH epithelial BPH-1 and prostate myofibroblast WPMY-1 cells. Cell viability, apoptosis and immunoblotting were performed, followed by gene expression profiling and gene set enrichment analysis (GSEA) to detect the differentially expressed genes and signaling pathway induced by Pao extract. Human ex vivo BPH explant organ culture was also used to examine the effects of Pao extract on human BPH tissues.

Results: Pao extract treatment inhibited viability and induced apoptosis in human BPH-1 and WPMY-1 cells. Gene expression profiling and the following validation indicated that the expression levels of pro-apoptotic genes (eg. PCDC4, CHOP and FBXO32) were induced by Pao extract in both two cell lines. GSEA further revealed that Pao extract treatment was negatively associated with the activation of NFKB signaling. Pao extract suppressed the transcriptional activity of NFKB and down-regulated its target genes involved in inflammation (CXCL5, CXCL6 and CXCL12) and extracellular matrix (ECM) remodeling (HAS2, TNC and MMP13) in both cultured cells and human ex vivo BPH explants.

Conclusion: In both BPH epithelial and stromal cells, Pao extract induces apoptosis by upregulating the proapoptotic genes and inhibiting the inflammation-associated NFKB signaling via reducing phosphorylation of NFKB subunit RelA. Our data suggest that Pao extract may be a promising phytotherapeutic agent for BPH.
\end{abstract}

Keywords: Pao Pereira extract, BPH, NFKB, Inflammation, Extracellular matrix

\footnotetext{
* Correspondence: shenbingyishi@163.com; yan_jun@fudan.edu.cn;

rmhuang@simm.ac.cn

${ }^{\dagger}$ Yu Dong, Jiakuan Liu and Zesheng Xue contributed equally to this work.

${ }^{4}$ Department of Urology, Shanghai General Hospital, Shanghai Jiaotong

University, 100 Haining Road, Shanghai 200080, China

${ }^{5}$ Department of Laboratory Animal Science, Fudan University, 130 Dong'an

Road, Shanghai 200032, China

${ }^{2}$ Shanghai Institute of Materia Medica, Chinese Academy of Sciences, 555

Zuchongzhi Road, Shanghai 201203, China

Full list of author information is available at the end of the article
}

C C The Author(s). 2020 Open Access This article is licensed under a Creative Commons Attribution 4.0 International License, which permits use, sharing, adaptation, distribution and reproduction in any medium or format, as long as you give appropriate credit to the original author(s) and the source, provide a link to the Creative Commons licence, and indicate if changes were made. The images or other third party material in this article are included in the article's Creative Commons licence, unless indicated otherwise in a credit line to the material. If material is not included in the article's Creative Commons licence and your intended use is not permitted by statutory regulation or exceeds the permitted use, you will need to obtain permission directly from the copyright holder. To view a copy of this licence, visit http://creativecommons.org/licenses/by/4.0/. The Creative Commons Public Domain Dedication waiver (http://creativecommons.org/publicdomain/zero/1.0/) applies to the data made available in this article, unless otherwise stated in a credit line to the data. 


\section{Background}

Benign prostatic hyperplasia (BPH) is a non-malignant enlargement of the prostate gland that is common in older males. About $70 \%$ of men over 70 will develop $\mathrm{BPH}$ [1]. Due to the excessive proliferation of the epithelial and stromal cells in the transition zone and periurethral glands, the enlarged prostate ultimately induces lower urinary tract symptoms (LUTS) including urgency and difficulty of urination [2, 3]. Moderate-to-severe LUTS have significant influences on the patients' quality of life. The etiology of BPH is multi-factorial, including sex hormones, smooth muscle and inflammation [4]. Currently, medications for BPH/LUTS primarily target sex hormone synthesis and relief of tension in smooth muscle. However, alpha-blockers and $5 \alpha$-reductase inhibitors (5-ARIs) induce non-trivial adverse side effects including asthenia and ejaculatory dysfunction [5]. Hence, more effective agents with fewer side effects are needed.

Chronic inflammation has been implicated in BPH development, as manifested by the infiltration of immune cells, including activated $\mathrm{T}$ cells and macrophages into human $\mathrm{BPH}$ tissues [6]. It was reported that chronic prostatic inflammation was associated with a larger prostate volume and a higher International Prostate Symptom Score (IPSS) [7].

Pao pereira (Geissospermum vellosii) is an Amazon rainforest tree, and its bark extract is used to treat malaria, digestive disorders and cancers. Pao extract is rich in $\beta$-carboline alkaloids [8] and exhibited antiproliferative activities against melanoma and glioblastoma, ovarian cancer and pancreatic cancer [9-13]. Our previous study showed that Pao extract decreased human prostate cancer cell growth via inducing apoptosis [14]. Recently we found that Pao extract can attenuate $\mathrm{BPH}$ development in a rat model [15]. However, the molecular mechanism remains largely unclear.

In this study, we investigated the effects of Pao extract on human BPH epithelial cells (BPH-1) and stromal cells (WPMY-1). We found that Pao extract suppressed the growth of BPH-1 and WPMY-1 cells, and induced apoptosis via inhibition of $\mathrm{NF \kappa B}$ signaling pathway. An ex vivo human $\mathrm{BPH}$ explant was also exploited to test the effects of Pao extract. These findings suggest that Pao extract may be a very promising therapeutic agent for $\mathrm{BPH}$.

\section{Methods}

\section{Cell lines, human BPH tissues and reagents}

Human BPH-derived prostate epithelial BPH-1 cell line was kindly provided by Dr. Simon Hayward (Vanderbilt University Medical Center, Nashville, TN, USA). Human prostate myofibroblast WPMY-1 cell line was purchased from the Cell Bank of Type Culture Collection of
Chinese Academy of Sciences (Shanghai, China). BPH-1 and WPMY-1 cells were cultured in RPMI 1640 (Corning, New York, NY, USA) and DMEM medium (Corning), respectively, containing $10 \%$ fetal bovine serum (FBS; Life Technologies, Carlsbad, CA, USA) and penicillin-streptomycin (S110JV, BasalMedia, Shanghai, China). Passage number of BPH-1 and WPMY-1 cell lines was less than 20 for all the cell-based experiments. The study protocol using human BPH tissues was approved by the Ethics Committee of Shanghai General Hospital, Shanghai Jiaotong University. Human BPH tissues were collected also with patients' consent. Pao extract was from Natural Source International (New York, NY, USA). Briefly, the extract was prepared with aqueous alcoholic extraction of the bark of the plant Pao Pereira, which was then transformed into a free-flowing powder by spray drying. It contained $54 \% \beta$-carboline alkaloids, including flavopereirine, by high-performance liquid chromatography [13, 15]. The Pao extract was dissolved in DMSO and diluted with sterile phosphate buffered saline (PBS) to $50 \mathrm{mg} / \mathrm{ml}$ as a stock solution and stored at $-80^{\circ} \mathrm{C}$ until use. The final concentration of DMSO was less than $6 \%(\mathrm{v} / \mathrm{v})$.

\section{Antibodies}

Primary antibodies targeting the following proteins were used: Caspase-3 (\#9662, Cell Signaling Technology (CST), Danvers, MA, USA, 1:1000), Cleaved Caspase-3 (\#9661, CST, 1:1000), PARP (\#9532, CST, 1:1000), Cleaved PARP (\#5625, CST, 1:1000), NFkB/p65 (\#8242, CST, 1:1000), Phospho-NFkB/p65(Ser536) (\#3033, CST, 1:1000), PDCD4 (12587-1-AP, Proteintech, Rosemont, IL, USA, 1:1000), $\beta$-Actin (A2228, Sigma-Aldrich, St Louis, MO, USA, 1:5000), and CHOP (\#2895, CST, 1: 1000). Peroxidase AffiniPure goat anti-mouse IgG ( $\mathrm{H}+$ L) (115-035-003, 1:2500) and peroxidase AffiniPure goat anti-rabbit IgG $(\mathrm{H}+\mathrm{L})$ (111-035-003, 1:2500) were purchased from Jackson ImmunoResearch (West Grove, PA, USA) and used as the secondary antibodies.

\section{Cell cytotoxicity assay}

BPH-1 cells $\left(1.5 \times 10^{3}\right.$ cells/well $)$ and WPMY-1 cells $\left(2.5 \times 10^{3}\right.$ cells/well $)$ were seeded into 96 -well plates in triplicate. The next day Pao extract with different concentrations was added into culture medium. 24, 48 and $72 \mathrm{~h}$ later, the cells were fixed with $10 \%$ trichloroacetic acid (TCA; Sigma-Aldrich) over $4 \mathrm{~h}$ and stained with 4 $\mathrm{mg} / \mathrm{ml}$ sulforhodamine B (SRB; Sigma-Aldrich) in 1\% acetic acid. $10 \mathrm{mM}$ Tris base solution was used to dissolve the protein-bound dye. Optical density (OD) at $560 \mathrm{~nm}$ was determined by a microplate reader (SpectraMax M5, Molecular Devices, Sunnyvale, CA, USA). 


\section{Apoptosis assay}

Apoptosis assay was performed using FITC Annexin V Apoptosis Detection Kit I (\#556547, BD Biosciences, Franklin Lakes, NJ, USA). BPH-1 and WPMY-1 cells were seeded into 6 -well plates at densities of $5 \times 10^{4}$ cells/well and $1 \times 10^{5}$ cells/well, respectively. The next day, the medium was replaced with fresh medium and the cells were treated with Pao extract or cisplatin $(5 \mu \mathrm{M}$, a positive control) for $72 \mathrm{~h}$. Then the floating and adherent cells were collected, washed with PBS twice and re-suspended in $1 \times$ Binding Buffer as $1 \times 10^{6}$ cells/ ml. $100 \mu \mathrm{l}$ cell suspension was stained with $5 \mu \mathrm{l}$ of FITCAnnexin $\mathrm{V}$ and $5 \mu \mathrm{l}$ propidium iodide (PI) for $15 \mathrm{~min}$ at room temperature in the dark. Flow cytometry analysis was performed with a FACS Calibur flow cytometer (BD Biosciences) and cell death patterns were quantified (Figure S1) with FlowJo software (version 10.0.7r2, Ashland, OR, USA).

\section{Gene expression profiling analysis}

BPH-1 and WPMY-1 cells were treated with Pao extract for $24 \mathrm{~h}$, and total RNA was extracted with TRIzol reagent (Life Technologies). Affymetrix GeneChips (Human Transcriptome Array 2.0) were used for the gene expression profiling analysis (Shanghai Baygene Biotechnologies, Shanghai, China). The raw and normalized microarray data from this study can be accessed at GSE128856 in NCBI GEO Datasets. Gene Set Enrichment Analysis (GSEA) was performed using the GSEA software (v3.0, http://software.broadinstitute.org/gsea/ index.jsp) [16] to determine the association between the priori defined gene sets in the Molecular Signatures Database (MSigDB) and the different changes of genes induced by Pao extract treatment. The number of permutations was 1000. Enrichment statistic was weighted and the ranking metric was the difference of class means (Diff_of_Classes). Normalized enrichment score (NES) $\geq$ 1 and the false discovery rate $(\mathrm{FDR})<0.25$ were used as the cutoff.

\section{Western blotting}

Cells were lysed with 2\% SDS lysis buffer and total protein was quantified with the Enhanced BCA Protein Assay Kit (P0009, Beyotime, Shanghai, China). 10 $20 \mu \mathrm{g}$ total protein was separated on an SDS-PAGE gel and transferred onto a polyvinylidene difluoride (PVDF) membrane (Millipore, Billerica, MA, USA). The membranes were blocked with $5 \%$ bovine serum albumin (BSA; FA016, Gen-view Scientific, Houston, TX, USA) and incubated with the primary antibodies overnight at $4{ }^{\circ} \mathrm{C}$. Then the membranes were incubated with horseradish peroxidase (HRP)-conjugated secondary antibodies for $1 \mathrm{~h}$ at room temperature. The signals were developed with SuperSignal West Pico PLUS
Chemiluminescent Substrate (Thermo Fisher Scientific, Waltham, MA, USA) and detected by the Mini Chemiluminescent Imaging and Analysis System (Beijing Sage Creation Science, Beijing, China).

\section{RNA isolation and quantitative real-time PCR}

The total RNA from cells was extracted using TRIzol, according to the manufacturer's instructions. RNA was dissolved in DEPC-treated water (Sangon Biotech, Shanghai, China). The concentration and purity of RNA were measured with a NanoDrop One Microvolume UV-Vis Spectrophotometer (Thermo Fisher Scientific), and RNA was kept at $-80^{\circ} \mathrm{C}$. Residual DNAs in total RNAs were removed and cDNAs were synthesized by Hifair II 1st Strand cDNA Synthesis SuperMix (11123ES60, YEASEN, Shanghai, China) following the manufacturer's protocol. Quantitative real-time PCR was performed by ChamQ Universal SYBR qPCR Master Mix (Q711-02, Vazyme, Nanjing, China) using a CFX96 Touch Real-Time PCR Detection System (Bio-Rad, Hercules, CA, USA) with the reaction conditions: Stage $1,95^{\circ} \mathrm{C}$ for $30 \mathrm{~s}$; Stage 2, 40 cycles of $95^{\circ} \mathrm{C}$ for $10 \mathrm{~s}$ and $60^{\circ} \mathrm{C}$ for $30 \mathrm{~s}$; Stage $3,95^{\circ} \mathrm{C}$ for $15 \mathrm{~s}, 60^{\circ} \mathrm{C}$ for $60 \mathrm{~s}$ and $95^{\circ} \mathrm{C}$ for $15 \mathrm{~s}$. Data analysis was performed using the $\Delta \Delta \mathrm{Ct}$ method. Fold change was determined in relative quantification units using $A C T B$ gene for normalization. Primers were listed in Table S1.

\section{Dual-luciferase reporter gene assay}

BPH-1 and WPMY-1 cells were seeded into 24-well plates $\left(5 \times 10^{4}\right.$ cells/well). $200 \mathrm{ng} 6 \times \mathrm{NFkB}$-Luc plasmid and $50 \mathrm{ng}$ pRL-CMV plasmid for each well were transfected into the cells at $\sim 70 \%$ confluency by Lipofectamine 3000 (Invitrogen, Carlsbad, CA, USA) in the presence of FBS. Eight hours after transfection, Pao extract was added for $36 \mathrm{~h}$ (BPH-1 cells) and $40 \mathrm{~h}$ (WPMY-1 cells), respectively. Cell lysates were then measured by Dual-Luciferase Reporter Assay System (E1910, Promega, Madison, WI, USA). The ratio of firefly luciferase activity versus Renilla luciferase activity was determined for NFKB transcriptional activity.

\section{BPH ex vivo explant culture}

Human BPH tissues $(n=4)$ were obtained from patients with a transurethral resection of the prostate at Shanghai General Hospital, Shanghai Jiaotong University. The $\mathrm{BPH}$ ex vivo explant culture was described previously $[17,18]$. In brief, the BPH tissues were subdivided into $3-5 \mathrm{~mm}^{3}$ pieces and cultured on absorbable gelatin sponges (HSD-B, HUSHIDA, Nanchang, China) in 6well plates containing $4 \mathrm{ml}$ DMEM/F-12 (Corning) with $10 \%$ FBS, antibiotic /antimycotic solution (S120, BasalMedia), $0.01 \mathrm{mg} / \mathrm{ml}$ insulin (I1882, Sigma-Aldrich) and $0.01 \mathrm{mg} / \mathrm{ml}$ hydrocortisone (H0135, Sigma-Aldrich). 
Tissues were treated with Pao extract for $48 \mathrm{~h}$ at $37^{\circ} \mathrm{C}$. The tissues were washed with PBS twice and then grinded with the High Throughput Tissue Grinder (Scientz-48, Ningbo Scientz Biotechnology, Ningbo, China) in protein lysis buffer or TRIzol.

\section{Statistical analysis}

Statistical analyses were performed using GraphPad Prism Software (version 8.0.1, GraphPad, San Diego, CA, USA). Two-tailed Student's $t$ test was used to compare the difference between two groups, and $P<0.05$ was considered statistically significant.

\section{Results}

Pao extract inhibited proliferation of BPH-1 and WPMY-1 cells

To evaluate the effect of Pao extract on the growth of cells derived from the prostate, $\mathrm{BPH}-1$ and WPMY-1 cells were exposed to Pao extract with dosages ranging from 125 to $500 \mu \mathrm{g} / \mathrm{ml}$, and the cell proliferation were assessed by SRB assay. Pao extract treatment significantly reduced the adherent cell number at 48 h (Fig. 1a) and viability within $72 \mathrm{~h}(p<$ $0.05)$ in a concentration-dependent manner in both cell lines (Fig. 1b).

a

BPH-1 cells treated with Pao extract
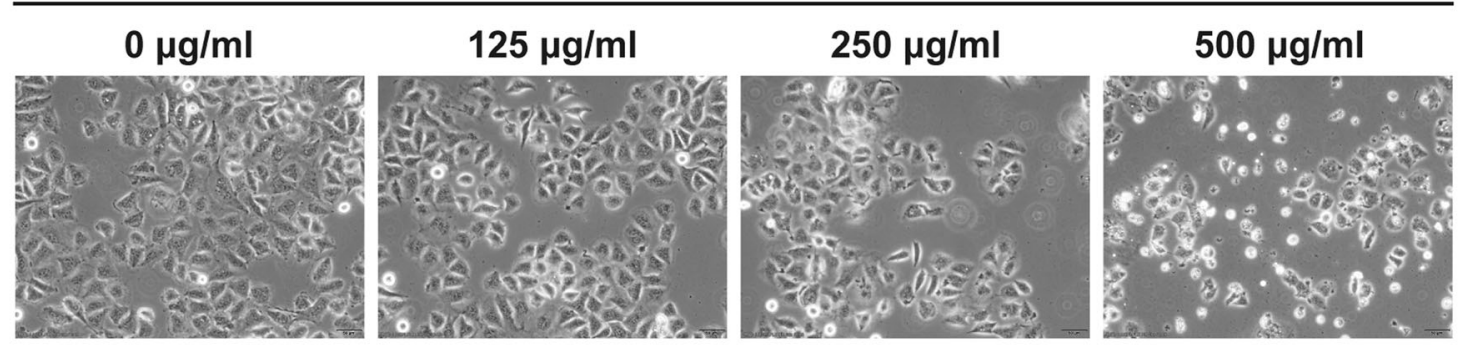

$100 \mu \mathrm{m}$

WPMY-1 cells treated with Pao extract
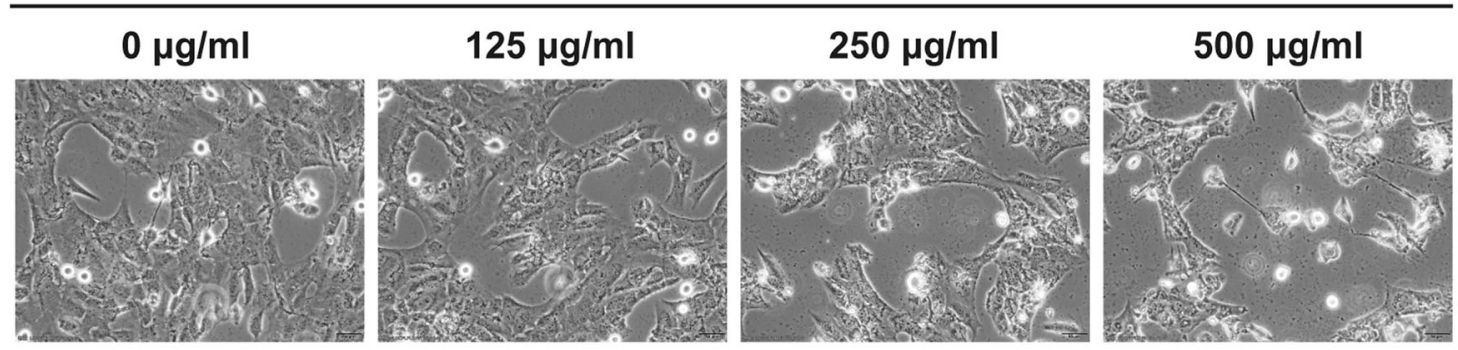

$100 \mu \mathrm{m}$

b

BPH-1
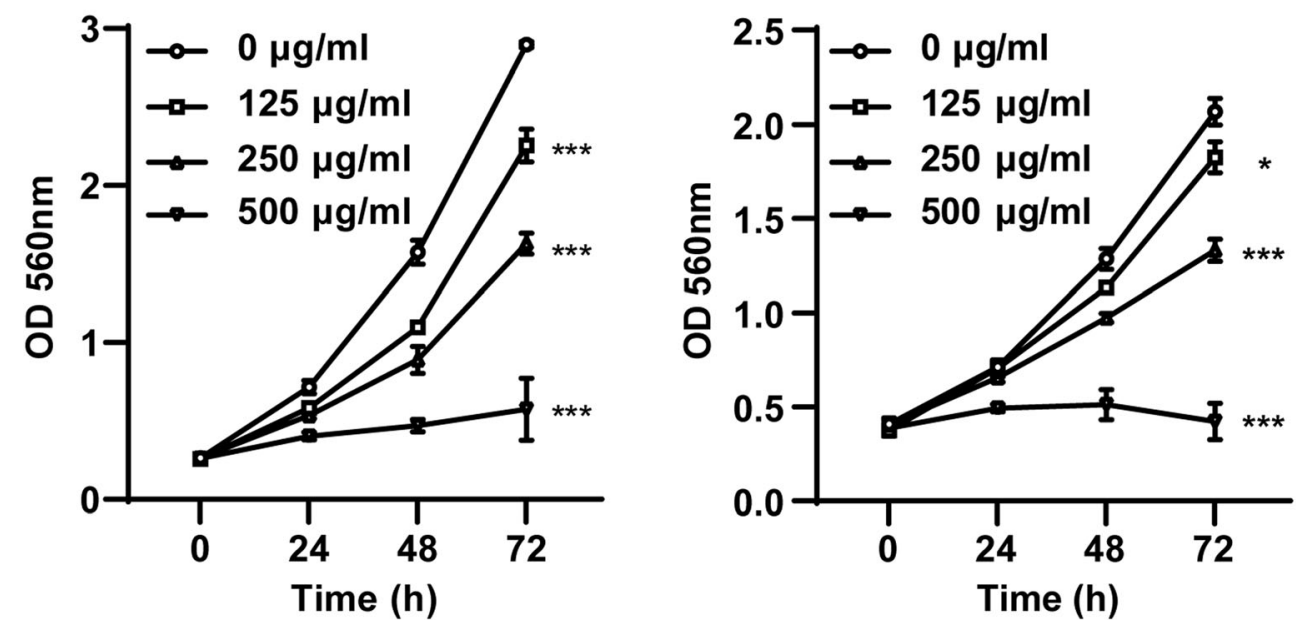

Fig. 1 Pao extract inhibited the proliferation and induced apoptosis in BPH-1 and WPMY-1 cells. a Morphological changes of BPH-1 and WPMY-1 cells upon Pao extract treated for $48 \mathrm{~h}$. $\mathbf{b}$ Effects of Pao extract on cell viability by the SRB assay. BPH-1 and WPMY-1 cells were treated with Pao extract at the indicated concentrations for $0,24,48$ and $72 \mathrm{~h}$. Data are presented as mean \pm SD; ${ }^{*} p<0.05$, ${ }^{* *} p<0.01$, and ${ }^{* * *} p<0.001$ 


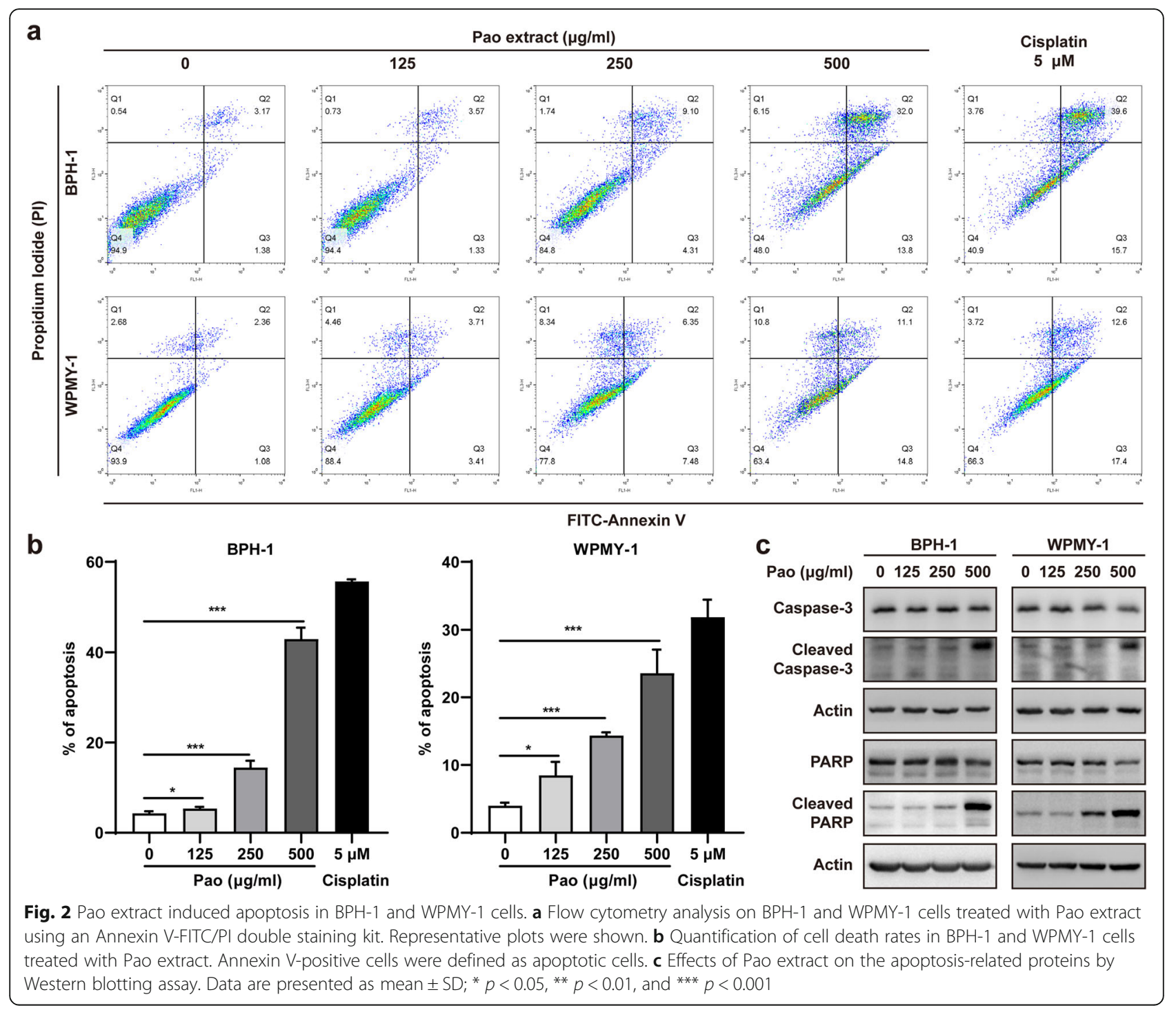

Pao extract induced apoptosis in BPH-1 and WPMY-1 cells Flow cytometry analyses were performed to determine whether Pao extract could induce apoptosis in BPH-1 and WPMY-1 cells. After $72 \mathrm{~h}$ treated with Pao extract, both cells showed that the percentages of apoptotic cells were significantly increased in a concentration-dependent manner by Annexin V-FITC/PI double staining (Fig. 2a). Notably, apoptosis was detected in $\sim 43 \% \mathrm{BPH}$ cells and $~$ 24\% WPMY-1 cells under the Pao extract treatment at $500 \mu \mathrm{g} / \mathrm{ml}$ (Fig. 2b). Moreover, the levels of cleaved Caspase- 3 and cleaved PARP were consistently increased in the Pao extract-treated cells (Fig. 2c).

\section{Pao extract regulated the pro-apoptotic and} inflammation-associated genes in BPH-1 and WPMY-1 cells To investigate which genes were regulated by Pao extract in both BPH-1 and WPMY-1 cells, gene expression profiling was performed using the Affymetrix microarray chips.
Using 1.4-fold as the cutoff, 106 up-regulated genes and 68 down-regulated genes were identified in Pao extract-treated BPH-1 cells, comparing to the vehicle-treated cells (Fig. 3a, left panel); 212 up-regulated genes and 511 down-regulated genes were identified in Pao extract-treated WPMY-1 cells (Fig. 3a, right panel). Among them, several pro-apoptotic and inflammation-associated genes were induced by $250 \mu \mathrm{g} / \mathrm{ml}$ Pao extract treatment (Fig. 3b). We further confirmed the induction of the pro-apoptotic genes (PDCD4, FBXO32 and DDIT3) in both BPH-1 and WPMY-1 cells by Pao extract at mRNA level (Fig. 3c). Western blotting data also indicated that Pao extract increases PDCD4 and DDIT3/CHOP at protein level (Fig. 3d).

\section{Pao extract inhibited NFKB signaling pathway in BPH-1 and WPMY-1 cells}

We also used the aforementioned microarray data to investigate which signaling pathways were regulated by 


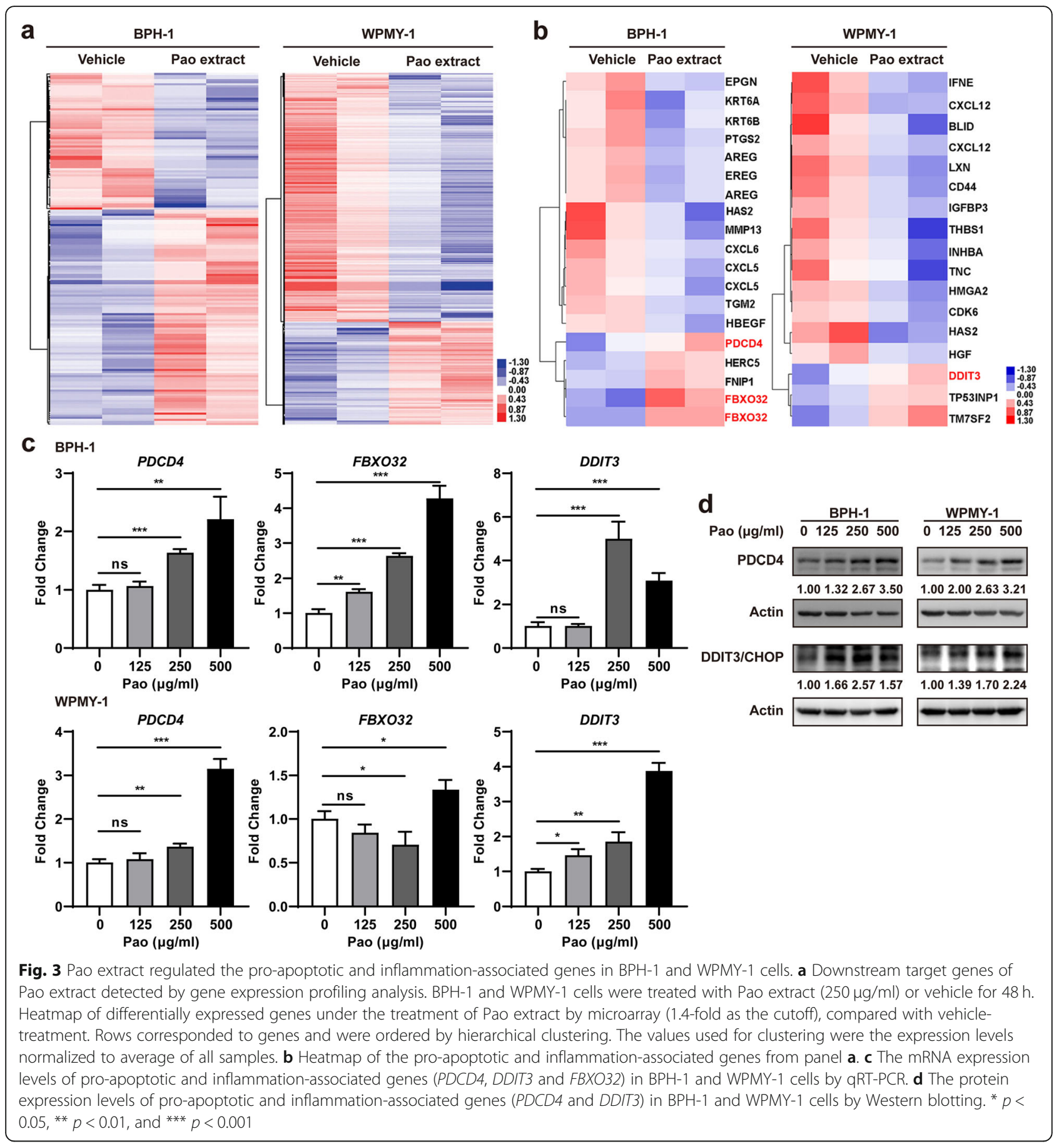

Pao extract in both BPH-1 and WPMY-1 cells by GSEA. The association between the down-regulation in gene set of $\mathrm{NFK}_{\mathrm{K}} \mathrm{B}$ signaling pathway and Pao extract treatment was identified in both $\mathrm{BPH}-1$ cells $(\mathrm{NES}=2.17, \mathrm{FDR}<$ 0.001 ) and WPMY-1 cells $(\mathrm{NES}=1.24, \mathrm{FDR}=0.12$ ), respectively (Fig. 4a). The phosphorylation levels of RelA (a subunit NFKB transcription complex) were also shown to be reduced in BPH-1 and WPMY-1 cells by Pao extract using Western blotting (Fig. 4b). Moreover, NFKB- reporter was transiently transfected into $\mathrm{BPH}-1$ and WPMY-1 cells, followed by Pao extract treatment. The luciferase activity from $\mathrm{NF}_{\mathrm{K} B}$-reporter was suppressed by $60 \%$ in BPH-1 cells $(p<0.01)$ and by $62 \%$ in WPMY1 cells $(\mathrm{p}<0.01)$ using $500 \mu \mathrm{g} / \mathrm{ml}$ Pao extract (Fig. 4c). The expression levels of several well-known NFkB target genes involved in inflammation (CXCL5, CXCL6, and CXCL12) and extracellular matrix (ECM) remodeling (HAS2, TNC, and MMP13) were further tested. 


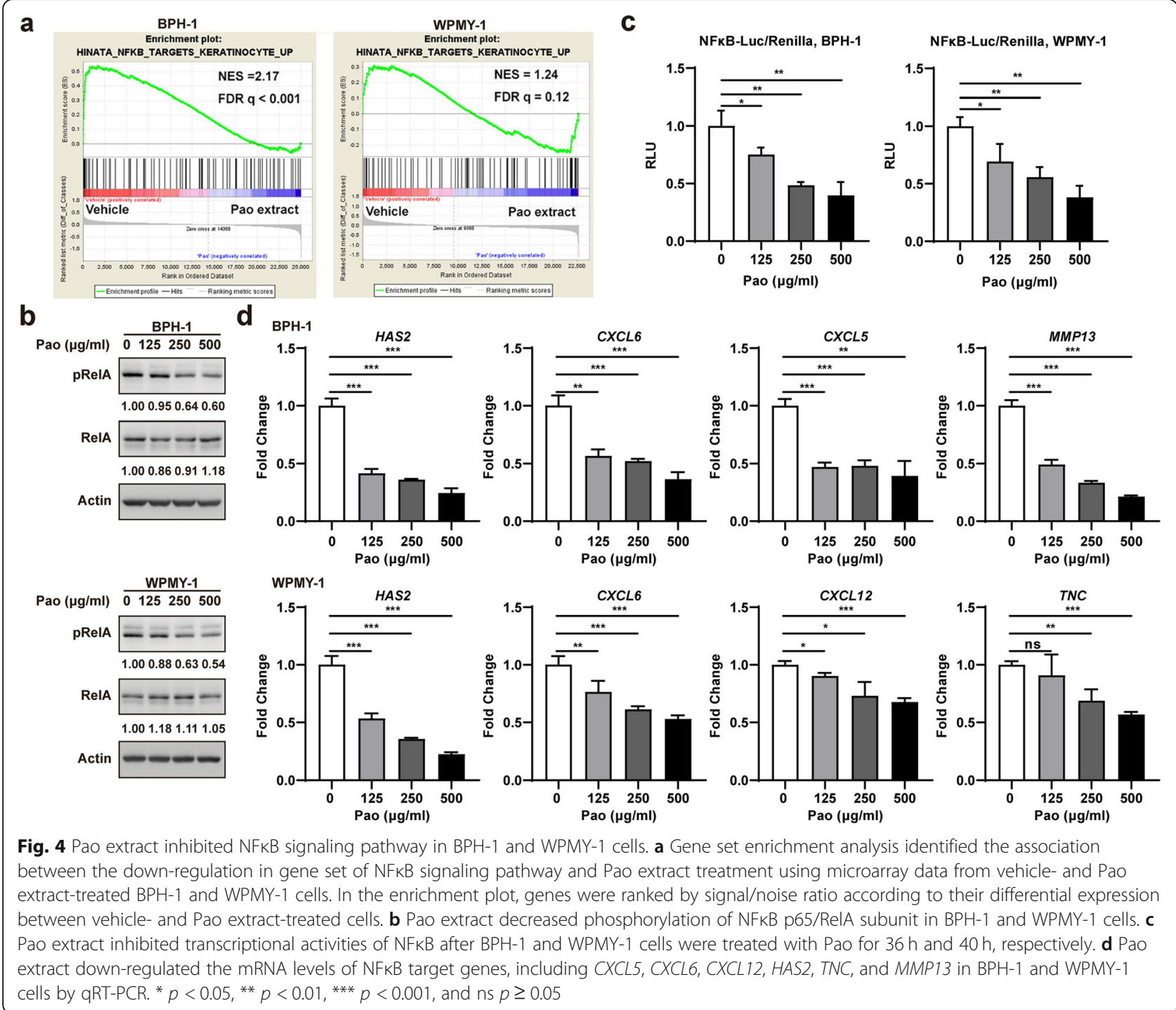

Consistently, HAS2, CXCL6, CXCL5, and MMP13 were down-regulated in BPH-1 cells and HAS2, CXCL6, CXCL12, TNC were down-regulated in WPMY-1 cells by Pao extract (Fig. 4d). Altogether, it was suggested that Pao extract suppresses the activation of NFKB signaling in both BPH epithelial and stromal cells.

\section{Pao extract inhibited NFKB signaling pathway in human BPH tissues}

To validate the effects of Pao extract on human $\mathrm{BPH}$, an ex vivo explant culture system was established for the tissues from $\mathrm{BPH}$ patients (Fig. 5a). $\mathrm{BPH}$ explants were treated with 0,250 and $500 \mu \mathrm{g} / \mathrm{ml}$ Pao extract for $48 \mathrm{~h}$, following the assessment of $\mathrm{NF} \times \mathrm{B}$ signaling. Consistent with the data from cultured cell lines, the phosphorylation levels of RelA were markedly decreased and the protein levels of PDCD4 and DDIT3/CHOP were increased in Pao extract-treated $\mathrm{BPH}$ explants (Fig. 5b). In addition, the mRNA expression levels of the downstream target genes of $\mathrm{NFKB}$ signaling, including CXCL6, HAS2, CXCL5, CXCL12, MMP13 and TNC, were also significantly reduced $(p<0.01)$, as well as the up-regulation of the apoptosis-associated genes PDCD4, DDIT3 and FBXO32 $(p<0.05)$, in BPH explants treated with Pao extract (Fig. 5c). Taken together, it was demonstrated that Pao extract inhibited the NFKB signaling pathway in human $\mathrm{BPH}$ tissues.

\section{Discussion}

Our previous study demonstrated that Pao extract suppresses testosterone-induced $\mathrm{BPH}$ in a rat model. To examine its effects on human $\mathrm{BPH}$ sample and delineate its molecular mechanism, herein we found that Pao extract inhibited the viabilities of $\mathrm{BPH}$ epithelial cells and stromal cells in a dose-dependent manner, due to the increase of apoptosis and suppression of NFkB signaling. 


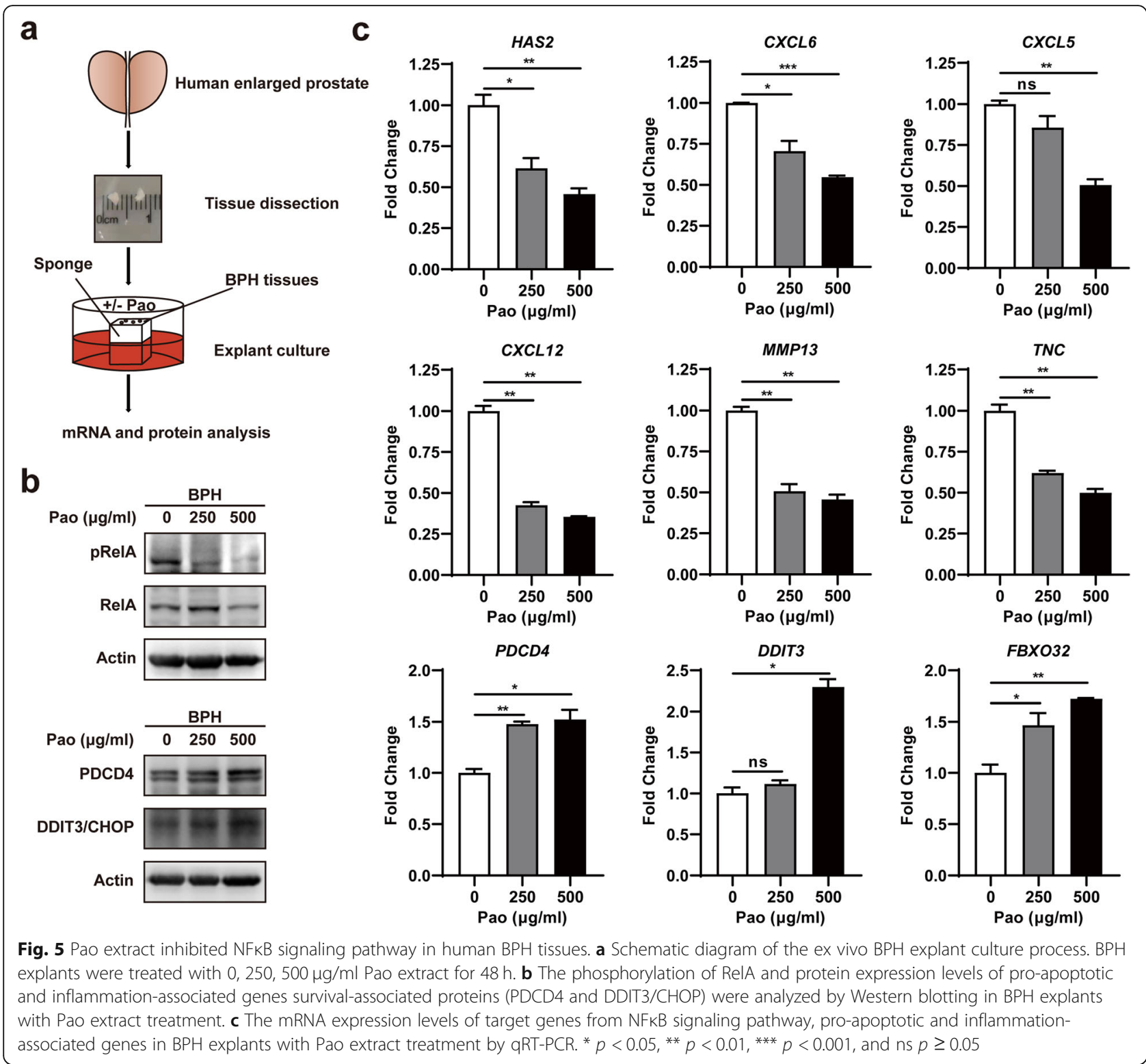

Downregulation of inflammation- and ECM remodelingrelated genes via $\mathrm{NFKB}$ signaling was further demonstrated in human $\mathrm{BPH}$ cell lines in vitro and in human $\mathrm{BPH}$ explants ex vivo (Fig. 6).

The canonical $\mathrm{NF}_{\mathrm{K} B} \mathrm{~B}$ pathway is frequently upregulated during the progression of $\mathrm{BPH}$, and the severity of BPH is correlated with activation of $\mathrm{NFK}_{\mathrm{K}}$ [19], which makes it an interesting target for BPH. For example, Elocalcitol was reported to inhibit BPH stromal cells proliferation by targeting $\mathrm{NF} \mathrm{KB} / \mathrm{p} 65$ nuclear translocation [20]. Here, we showed that Pao extract could inhibit the phosphorylation level of RelA (Ser536), leading to the decrease of transcriptional activity of $\mathrm{NF} \mathrm{KB}$ complex. In addition, Pao extract increased the mRNA and protein expression levels of two pro-apoptotic proteins, PDCD4 and DDIT3/CHOP. PDCD4 was reported to directly bind with $\mathrm{NF} \kappa \mathrm{B} / \mathrm{p} 65$ and suppressed NFkB-dependent transcription in human glioblastoma [21]. Hence, it is suggested that Pao extract may target $\mathrm{NF} \times \mathrm{B}$ activity in $\mathrm{BPH}$ at different levels.

As an age-related disease, BPH progression is accompanied by chronic inflammation and ECM remodeling around $\mathrm{BPH}$ nodules. The inflammatory $\mathrm{BPH}$ microenvironment contains various secreted cytokines and chemokines, including CXCL5, CXCL6 and CXCL12, which are the direct $\mathrm{NF}_{\mathrm{K} B}$ target genes [22-24] and can promote the proliferation of both prostatic epithelial cells and stromal fibroblasts [25-27]. For the ECMassociated genes, such as HAS2, MMP13 and TNC, they are also target genes of $\mathrm{NF}_{\kappa} \mathrm{B}$ signaling. HAS2 gene 


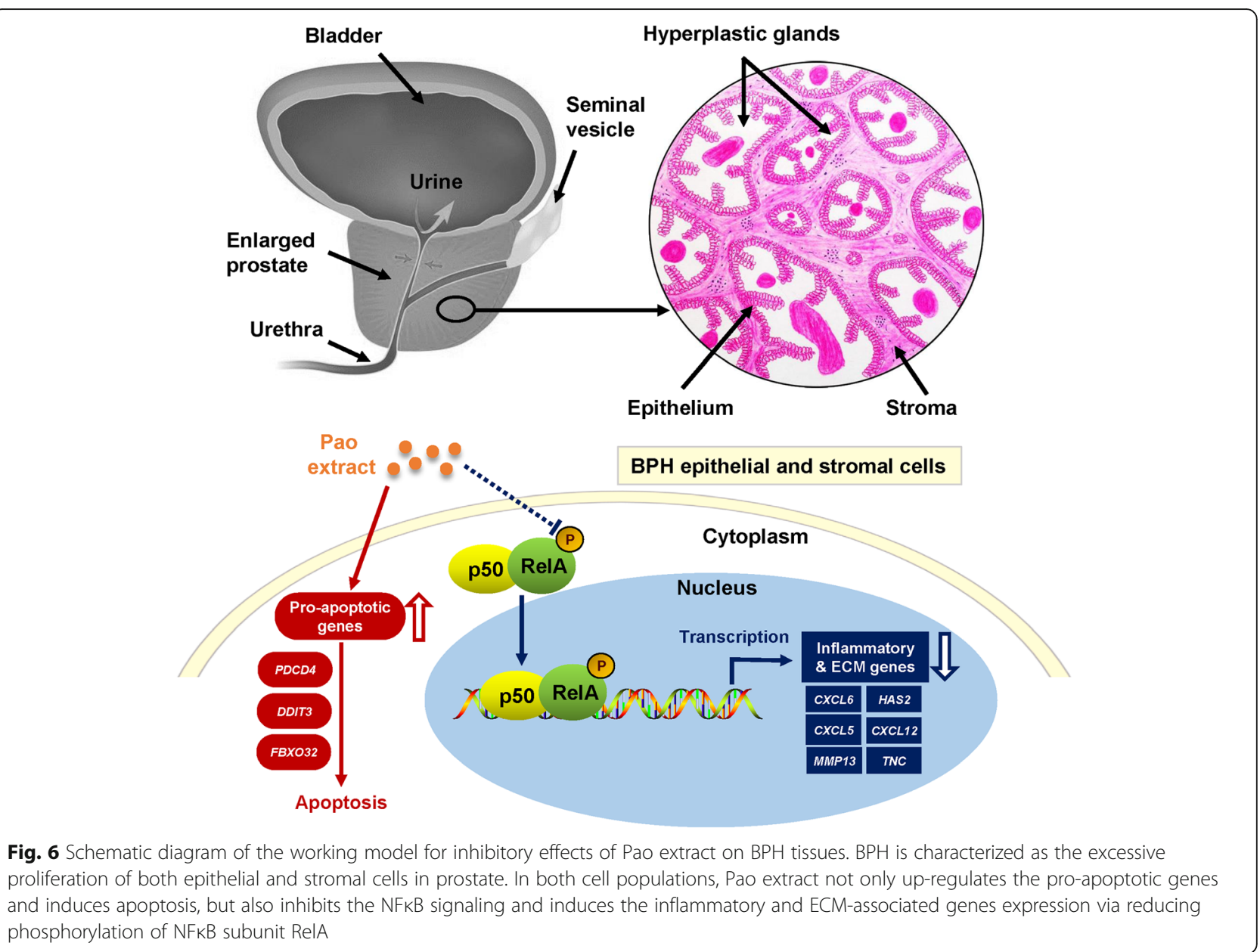

encodes hyaluronan synthase 2 , an enzyme that synthesizes hyaluronan (HA) in BPH tissues [28, 29]. When $\mathrm{BPH}-1$ cells were cultured in 3D gel containing collagen, they proliferated faster in the collagen from aged mice (high level of HA) than that from young mice (low level of HA). Previous studies also showed that MMP13 promoted ECM degradation, and the elevated ECM glycoprotein Tenascin- $\mathrm{C}$ was associated with myofibroblast in BPH tissues [30, 31]. Here, we observed that Pao extract downregulates the expression levels of CXCL5, CXCL6, CXCL12, HAS2, MMP13 and TNC in BPH-1 and WPMY-1 cells, thus indicating that Pao extract attenuates the inflammation and ECM-remodeling via inhibition of NFKB signaling in $\mathrm{BPH}$.

\section{Conclusions}

Our data have proved the inhibitory effect of Pao extract on $N_{F} \mathrm{~B}$ signaling pathway in two cell lines derived from human $\mathrm{BPH}$ and ex vivo explants from human $\mathrm{BPH}$ patients. Using Pao extract as a negative regulator of $\mathrm{NF}_{\mathrm{K} B}$ signaling may be a promising phytotherapeutic agent for $\mathrm{BPH}$.

\section{Supplementary information}

Supplementary information accompanies this paper at https://doi.org/10. 1186/s12906-020-02943-2.

Additional file 1: Figure S1. Flow cytometry analysis on vehicle treated-BPH-1 cells (a) and WPMY-1 cells (b) stained with negative control buffer (Unstained), FITC-Annexin-V dye only (FITC only) and PI dye only (PI only). Representative plots were shown.

Additional file 2: Table S1. The sequences of primers used in quantitative real-time PCR assay.

\section{Abbreviations}

BPH: Benign prostatic hyperplasia; GSEA: Gene set enrichment analysis; LUTS: Lower urinary tract symptoms; 5-ARIs: 5a-reductase inhibitors; IPSS: International Prostate Symptom Score; TCA: Trichloroacetic acid; SRB: Sulforhodamine B; OD: Optical density; PI: Propidium iodide; BSA: Bovine serum albumin; HRP: Horseradish peroxidase; ECM: Extracellular matrix; HA: Hyaluronan

\section{Acknowledgements}

We thank the Institutional Technology Service Center of Shanghai Institute of Materia Medica for technical support.

Authors' contributions

$J Y$ and RH designed the work; YD, JL, ZX and JS performed the research and analyzed the data; $Z H, Y J, B H$ and $B S$ provide the resource. $Y D, J L$ and $Z X$ 
drafted the work; YD, JY and RH revised the paper. BS, JY and RH supervised the study. All authors read and approved the final manuscript.

\section{Funding}

This study was supported by the National Natural Science Foundation (81672873 and 81872373 to JY), the National Science \& Technology Major Project "Key New Drug Creation and Manufacturing Program", China (2018ZX09711002 to RH), One Hundred Talent Program of Chinese Academy of Sciences (to RH), Wu Jieping Medical Foundation (320.6750.16051 to BS), Shanghai Songjiang Municipal Science and Technology Commission Natural Science Foundation (17SJKJGG10 to BS), Shanghai Specialized Research Fund for Integrated Chinese and Western Medicine in General Hospitals (ZHYYZXYJHZX-1-201705 to BS) and The Beljanski Foundation to JY. The founding sponsor had no role in the design of the study; in the collection, analyses, or interpretation of data; in the writing of the paper; and in the decision to publish the results.

\section{Availability of data and materials}

All microarray files are available from the NCBI GEO Datasets (accession number GSE128856). Other datasets used and/or analyzed during the current study are available from the corresponding author on reasonable request.

\section{Ethics approval and consent to participate}

The study protocol using human BPH tissues was approved by the Ethics Committee of Shanghai General Hospital, Shanghai Jiaotong University (2018KY067). Human BPH tissues were collected with patients' oral consent.

\section{Consent for publication}

Not applicable.

\section{Competing interests}

The authors declare that they have no competing interests.

\section{Author details}

${ }^{1}$ Shanghai University, Shanghai, China. ${ }^{2}$ Shanghai Institute of Materia Medica, Chinese Academy of Sciences, 555 Zuchongzhi Road, Shanghai 201203, China. ${ }^{3}$ Model Animal Research Center of Nanjing University, Nanjing, Jiangsu, China. ${ }^{4}$ Department of Urology, Shanghai General Hospital, Shanghai Jiaotong University, 100 Haining Road, Shanghai 200080, China. ${ }^{5}$ Department of Laboratory Animal Science, Fudan University, 130 Dong'an Road, Shanghai 200032, China. ${ }^{6}$ MOE Key Laboratory of Model Animals for Disease Study, Model Animal Research Center of Nanjing University, Nanjing, Jiangsu, China. ${ }^{7}$ University of Chinese Academy of Sciences, Beijing 100049, China.

Received: 27 January 2020 Accepted: 4 May 2020

Published online: 16 May 2020

\section{References}

1. Hellwege JN, Stallings S, Torstenson ES, Carroll R, Borthwick KM, Brilliant MH, et al. Heritability and genome-wide association study of benign prostatic hyperplasia (BPH) in the eMERGE network. Sci Rep. 2019;9(1):6077.

2. Bushman W. Etiology, epidemiology, and natural history of benign prostatic hyperplasia. Urol Clin North Am. 2009;36(4):403-15 v.

3. Lepor H. Pathophysiology, epidemiology, and natural history of benign prostatic hyperplasia. Rev Urol. 2004;6(Suppl 9):S3.

4. Chughtai B, Forde JC, Thomas DDM, Laor L, Hossack T, Woo HH, et al. Benign prostatic hyperplasia. Nat Rev Dis Primers. 2016;2:16031.

5. Kapoor A. Benign prostatic hyperplasia (BPH) management in the primary care setting. Can J Urol. 2012;19(Suppl 1):10-7.

6. Theyer G, Kramer G, Assmann I, Sherwood E, Preinfalk W, Marberger M, et al. Phenotypic characterization of infiltrating leukocytes in benign prostatic hyperplasia. Lab Investig. 1992;66(1):96-107.

7. Robert G, Descazeaud A, Nicolaïew N, Terry S, Sirab N, Vacherot F, et al. Inflammation in benign prostatic hyperplasia: a 282 patients' immunohistochemical analysis. Prostate. 2009;69(16):1774-80.

8. Bemis DL, Capodice JL, Desai M, Katz AE, Buttyan R. $\beta$-Carboline alkaloidenriched extract from the Amazonian rain forest tree pao Pereira suppresses prostate cancer cells. J Soc Integr Oncol. 2009;7(2):59.

9. Yu J, Drisko J, Chen Q. Inhibition of pancreatic cancer and potentiation of gemcitabine effects by the extract of Pao Pereira. Oncol Rep. 2013;30(1): 149-56.
10. Dong R, Chen P, Chen Q. Extract of the medicinal plant Pao Pereira inhibits pancreatic cancer stem-like cell in vitro and in vivo. Integr Cancer Ther. 2018;17(4):1204-15.

11. Beljanski $\mathrm{M}, \mathrm{Crochet} \mathrm{S}$. The selective anticancer agent pb-100 inhibits interleukin-6 induced enhancement of glioblastoma cell-proliferation invitro. Int J Oncol. 1994;5(4):873-9.

12. Beljanski $\mathrm{M}$, Crochet $\mathrm{S}$. The anticancer agent pb-100 concentrates in the nucleus and nucleoli of human glioblastoma cells but does not enter normal astrocytes. Int J Oncol. 1995;7(1):81-5.

13. Yu J, Chen Q. The plant extract of Pao Pereira potentiates carboplatin effects against ovarian cancer. Pharm Biol. 2014:52(1):36-43.

14. Chang C, Zhao W, Xie B, Deng Y, Han T, Cui Y, et al. Pao Pereira extract suppresses castration-resistant prostate cancer cell growth, survival, and invasion through inhibition of NfkB signaling. Integr Cancer Ther. 2014;13(3):249-58.

15. Liu J, Fang T, Li M, Song Y, Li J, Xue Z, et al. Pao Pereira extract attenuates testosterone-induced benign prostatic hyperplasia in rats by inhibiting $5 \mathrm{a}-$ reductase. Sci Rep. 2019;9(1):19703.

16. Subramanian A, Tamayo P, Mootha VK, Mukherjee S, Ebert BL, Gillette MA, et al. Gene set enrichment analysis: a knowledge-based approach for interpreting genome-wide expression profiles. Proc Natl Acad Sci U S A. 2005;102(43):15545-50.

17. Centenera MM, Gillis JL, Hanson AR, Jindal S, Taylor RA, Risbridger GP, et al. Evidence for efficacy of new Hsp90 inhibitors revealed by ex vivo culture of human prostate tumors. Clin Cancer Res. 2012;18(13):3562-70.

18. Schiewer MJ, Goodwin JF, Han S, Brenner JC, Augello MA, Dean JL, et al. Dual roles of PARP-1 promote cancer growth and progression. Cancer Discov. 2012;2(12):1134-49.

19. Austin DC, Strand DW, Love HL, Franco OE, Jang A, Grabowska MM, et al. NF-KB and androgen receptor variant expression correlate with human $\mathrm{BPH}$ progression. Prostate. 2016;76(5):491-511.

20. Penna G, Fibbi B, Amuchastegui S, Corsiero E, Laverny G, Silvestrini E, et al. The vitamin $\mathrm{D}$ receptor agonist elocalcitol inhibits IL-8-dependent benign prostatic hyperplasia stromal cell proliferation and inflammatory response by targeting the RhoA/rho kinase and NF-kappaB pathways. Prostate. 2009;69(5):480-93.

21. Hwang S-K, Baker AR, Young MR, Colburn NH. Tumor suppressor PDCD4 inhibits NF-KB-dependent transcription in human glioblastoma cells by direct interaction with p65. Carcinogenesis. 2014:35(7):1469-80.

22. Guan Z, Li C, Fan J, He D, Li L. Androgen receptor (AR) signaling promotes RCC progression via increased endothelial cell proliferation and recruitment by modulating AKT $\rightarrow$ NF-KB $\rightarrow$ CXCL5 signaling. Sci Rep. 2016;6:37085.

23. Lisi $\mathrm{S}$, Sisto $M$, Lofrumento DD, D'amore M. Sjögren's syndrome autoantibodies provoke changes in gene expression profiles of inflammatory cytokines triggering a pathway involving TACE/NF-KB. Lab Investig. 2012;92(4):615.

24. Madge LA, May MJ. Classical NF-kappaB activation negatively regulates noncanonical NF-kappaB-dependent CXCL12 expression. J Biol Chem. 2010; 285(49):38069-77.

25. Begley LA, Kasina S, MacDonald J, Macoska JA. The inflammatory microenvironment of the aging prostate facilitates cellular proliferation and hypertrophy. Cytokine. 2008;43(2):194-9.

26. Maroni $P$, Bendinelli $P$, Matteucci $E$, Desiderio MA. HGF induces CXCR4 and CXCL12-mediated tumor invasion through Ets1 and NF-kappaB. Carcinogenesis. 2007;28(2):267-79.

27. Smith JB, Wadleigh DJ, Xia YR, Mar RA, Herschman HR, Lusis AJ. Cloning and genomic localization of the murine LPS-induced CXC chemokine (LIX) gene, Scyb5. Immunogenetics. 2002;54(8):599-603.

28. Damodarasamy M, Vernon RB, Chan CK, Plymate SR, Wight TN, Reed MJ. Hyaluronan in aged collagen matrix increases prostate epithelial cell proliferation. In Vitro Cell Dev Biol Anim. 2015;51(1):50-8.

29. Yoo KC, Suh Y, An Y, Lee HJ, Jeong YJ, Uddin N, et al. Proinvasive extracellular matrix remodeling in tumor microenvironment in response to radiation. Oncogene. 2018:37(24):3317-28.

30. Nakoshi Y, Hasegawa M, Sudo A, Yoshida T, Uchida A. Regulation of tenascin- $C$ expression by tumor necrosis factor-alpha in cultured human osteoarthritis chondrocytes. J Rheumatol. 2008;35(1):147-52.

31. Ishii K, Imanaka-Yoshida K, Yoshida T, Sugimura Y. Role of stromal tenascin-C in mouse prostatic development and epithelial cell differentiation. Dev Biol. 2008;324(2):310-9.

\section{Publisher's Note}

Springer Nature remains neutral with regard to jurisdictional claims in published maps and institutional affiliations. 